\title{
Flash Flood Early Warning Research in China
}

\author{
Haichen Li, Tao Qin and Xiaohui Lei \\ Additional information is available at the end of the chapter
}

http://dx.doi.org/10.5772/intechopen.69784

\begin{abstract}
Along with global climate change, extreme rainfall causes severe flash flood disasters, especially in mountainous areas. As about $67 \%$ of the terrestrial part of the whole country is mountain area with frequent heavy rainfall, China suffers from flash flood disasters throughout its history. As flash floods are distributed extensively and its influence sphere highly concentrated, it is unreasonable and uneconomical to prevent flash flood disasters mainly via engineering measures. Then, China starts exploring about flash flood early warning, which is optimal for developing country with dense populations, since the 1990s. Based on the literature research, a systematic framework for Chinese flash flood early warning research has been developed. In this frame, flash flood early warning is classified into long-term warning and real-time warning. This chapter presents the Chinese achievements in analysis methods for long-term warning, computational methods for real-time warning indicators, improving data sources used for real-time warnings and the information construction of real-time warning systems. In addition, the suggestions for future study are presented.
\end{abstract}

Keywords: flash flood, risk, early warning, China, review

\section{Introduction}

In China, flash floods are defined as floods which break out in mountain environments where villagers intensively inhabit, especially occurred in small watershed under $100 \mathrm{~km}^{2}$ [1, 2]. Flash floods usually rise up and down sharply, with high velocity and cause great losses [3]. As China is located in East Asian monsoon region, severe rainfall occurs frequently here. That often causes flash flood disasters, threatening villagers' life and restricting economic development of mountain areas [4]. Over the past years, the increase of extreme rainfall in China is generally attributed to the global climate change [5]. The increase of heavy rain leads to the 
increase of flash floods. The casualties of flash flood disasters are continually mounting those years. Thus, flash flood disasters become one of the most life-threatening water disasters in China [6].

As flash floods are distributed extensively and its influence sphere highly concentrated, it is unreasonable and uneconomical to prevent flash flood disasters mainly via engineering measures. To cope with this, the government of China draws up a guidance, prevention in the first place and integrating prevention with control, non-engineering measure as the main and combining it with engineering measures $[7,8]$. Since then flash flood early warning draws wide attention of China scholars. Against this background, it is essential to get an overall review of China research about flash flood early warning in the past years. Drawing lessons from the past, which is the main objective of this chapter, would provide effective references for engineering practice and outline the future prospects.

\section{The framework for China flash flood early warning research}

In the first place, temporal forecasting, spatial forecasting and developing of early warning system are considered as the three portions of the research system of flash flood early warning [9]. But in fact, early warning should give forecasting information as much as possible, better including both spot and time. So it is unreasonable to separate temporal forecasting with spatial forecasting. They should work together to tell people where and when disaster outbreak in advance. After synthetical consideration, we divide flash flood early warning research into two categories: long-term warning and real-time warning.

Based on the statistical regularity and disaster-causing mechanism, flash flood long-term warning is intended to forecast the occurrence possibility of flash floods in one mountain village or a zone in a relatively long period of time. This aspect of research can give decision maker an overall perspective of flash flood disasters to assist them with making out flash flood prevention and control plan. Also, this risk assessment can improve the government's ability of flash flood risk management and advertise to the public. The research framework of flash flood long-term warning is shown in Figure 1. In this framework, Chinese scholars mainly forecast flash floods based on statistical regularity rather than disaster-causing mechanism.

Different from the long-term warning, the flash flood real-time warning tries to tell us whether one mountain village will be in danger of flash flood in advent days, even in advent hours. Based on the long-term warning achievement and the flash flood disasters prevention

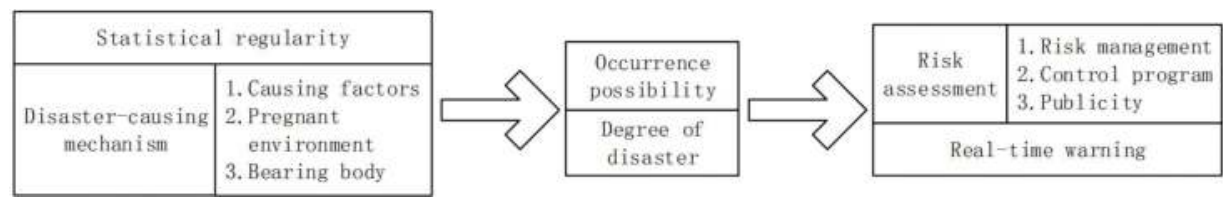

Figure 1. The research framework of flash flood long-term warning. 
and control situation, real-time warning indicators would be calculated by integrating multisources data to provide scientific basis for drawing up contingency plan and improving mass prediction and disaster prevention and so on.

Although the entire research framework of flash flood real-term warning is shown in Figure 2, but some sectors, such as indicator system and simulation of disaster, draw little attention of scholars. Besides this, increasing researchers turn their attention to multi-sources data acquiring and applying in calculation of flash flood real-time warning indicators to struggle with data deficient. Furthermore, some experts in software engineering start taking part in the construction of flash flood early warning system platforms, including data management system, information transmission system and application visualization system.

System platform: data management, information transmission, visualization

\begin{tabular}{|c|c|c|c|}
\hline & Long-term warning & & Contingency plan \\
\hline \multicolumn{2}{|c|}{ Disaster prevention and control } & Indicator system & \multirow{4}{*}{$\begin{array}{l}\text { Mass prediction and } \\
\text { disaster prevention } \\
\text { Warning information } \\
\text { announcement }\end{array}$} \\
\hline \multirow{4}{*}{$\begin{array}{c}\text { Multi- } \\
\text { sources } \\
\text { data }\end{array}$} & \multirow{4}{*}{$\begin{array}{l}\text { 1. Economy, Society } \\
\text { 2. Topography, Geomrophology } \\
\text { 3. Hydrology } \\
\text { 4. Meteorology } \\
\text { 5. Remote sensing }\end{array}$} & Calculation of & \\
\hline & & indicator & \\
\hline & & Simulation of & \\
\hline & & disaster & $\begin{array}{l}\text { Disaster control } \\
\text { consultation }\end{array}$ \\
\hline
\end{tabular}

Figure 2. The research framework of flash flood real-time warning.

\section{Research into long-term flash flood warning}

\subsection{Statistical analysis based on historical data}

In this section, an assumption is believed to be correct that the probability of flash flood disasters is a constant. Then, the recurrence cycle of historical disasters could be used for predicting the occurrence trend of future disasters [10]. Specifically, scholars collect historical disaster information of the target area to get one value via subtract one from the times of disasters and then divide the recording interval of disasters by this value. Then, the result reflects the activity degree of disaster and can be used for speculating the long-term probability of disaster. Using this method, the key is getting reliable, precise and adequate data of historical disasters [9].

This method used to analyse the risk of debris flow initially. For example, according to recurrence cycle of debris flow disaster, the developed phase of debris flow is divided into developing stage, active stage and decline stage [11]. As debris flows tend to occur along with flash flood, this probability analysis method was subsequently introduced into flash flood prediction. Applied to the flash flood research in Beijing, its mountain areas are divided into several zones of different level of debris flow and flash flood risk [12]. Afterwards, by this probability analysis method, plenty of works has been done in China to divide mountainous areas into several zones of risk for debris flows and flash flood. 


\subsection{Risk analysis based on disaster-causing mechanism}

Risk analysis based on disaster-causing mechanism focuses on spatial forecast without exact time prediction. In this long-term warning method, identification of flash floods and debris flow gully, risk assessment and risk zoning are main contents for estimating the location and danger level of flash floods and debris flow. Different in spatial scale of analysis, there are three types of conventional methods [13]. The first, researchers determine whether a gully is in danger of flash flood or not, then assess its potential degree of danger by a comprehensive index. The second, the scope broadens into a larger area, and the risk zones are delineated according to the distribution and risk assessment of flash floods. The third, the scope of attention focuses on the detail in one gully, and the hazardous part can be separated from safe spaces by using an appropriate model which is selected by the type of the gully. Many scholars work in studying of flash floods and debris flow risk zoning in China since 1985 with significant achievement, such as 1991 version of China debris flow disaster distribution and risk zoning map, discussion about debris flow disaster zoning in China, research on debris flow disaster zoning in the upper Yangtze river, etc. [14-18].

Along with rapid development of geographic information system (GIS) and remote sensing (RS) technologies, a new class of flash flood long-term warning methods based on GIS and RS have been tried by some scholars [19]. And by using GIS and RS data, flash flood disaster long-term warning prediction, or called risk assessment at that time, was calculated basing on conceptual formula (Eq. (1)). In this equation, the implication of long-term warning prediction covers the losses caused by disasters, the outburst probability of disasters and other consequence. The hazard comes from disaster danger zoning and represents the natural property of disasters. The vulnerability represents the social property influenced by disasters and is a financial analysis for measuring the disasters' destruction to human beings. Based on the positive correlation with the hazard and the vulnerability, the disaster risk can be calculated through mathematical operation of the hazard and the vulnerability.

Long-term warning prediction (disaster risk) $=$ hazard $\times$ vulnerability

Zhao assessed the risk of flash flood disasters on the upper reach area of Minjiang river by strength and frequency analysis [20]. Furthermore, Tang and Shi put forward an integrated technical route and method system, which covers data collection by GIS, spatial database construction, chosen of evaluation index system, forecast, risk assessment and zoning [21]. According to this technical route and method system, Guan and Chen drew up flash flood disasters risk assessment map of Jiangxi province, which based on geographical map and analysis of climate, rainfall, topography, gradient and river network and then overlaid this map with vulnerability assessment map for flash flood disaster risk zoning [22]. During analysing flash flood vulnerability in Wenshan city, range and depth of flash flood are considered as important indicators to improve accuracy of assessment [23, 24]. Lin et al. established a flash flood hazard zoning index system based on the micro-landforms, topography and slope position, flow accumulation and vegetation coverage and applied it to flash flood risk zoning in Tiaoshi town [25]. Latterly, by introducing land utilization as a new indicator into flash flood risk assessment, a more reasonable and reliable result of flash flood risk zoning in Jiangxi province is obtained [26]. 


\section{Research into real-term flash flood warning}

\subsection{Computational methods for real warning indicators}

Up to now, there still do not have a comprehensive indicator system that could take broader factors into account, such as wind direction and speed, velocity and quantity of flow, water level, rainfall intensity and quantity, etc. Instead, most scholars have been attracted to rainfall indicator, while a few other scholars focused on water-level warning indicator. The methods of calculating early warning rainfall can be divided into two classes: data driven and mechanism driven, as shown in Figure 3.

The data-driven method is the most primary way to calculate early warning rainfall amounts in practice. On the premise that flash floods must have certain correlation with rainfall amount, this sort of method calculates early warning precipitation by analysing historical disaster data without considering disaster mechanism. Chen and Yuan found an overall review of those methods and classified them into case survey method, single station critical rainfall, regional

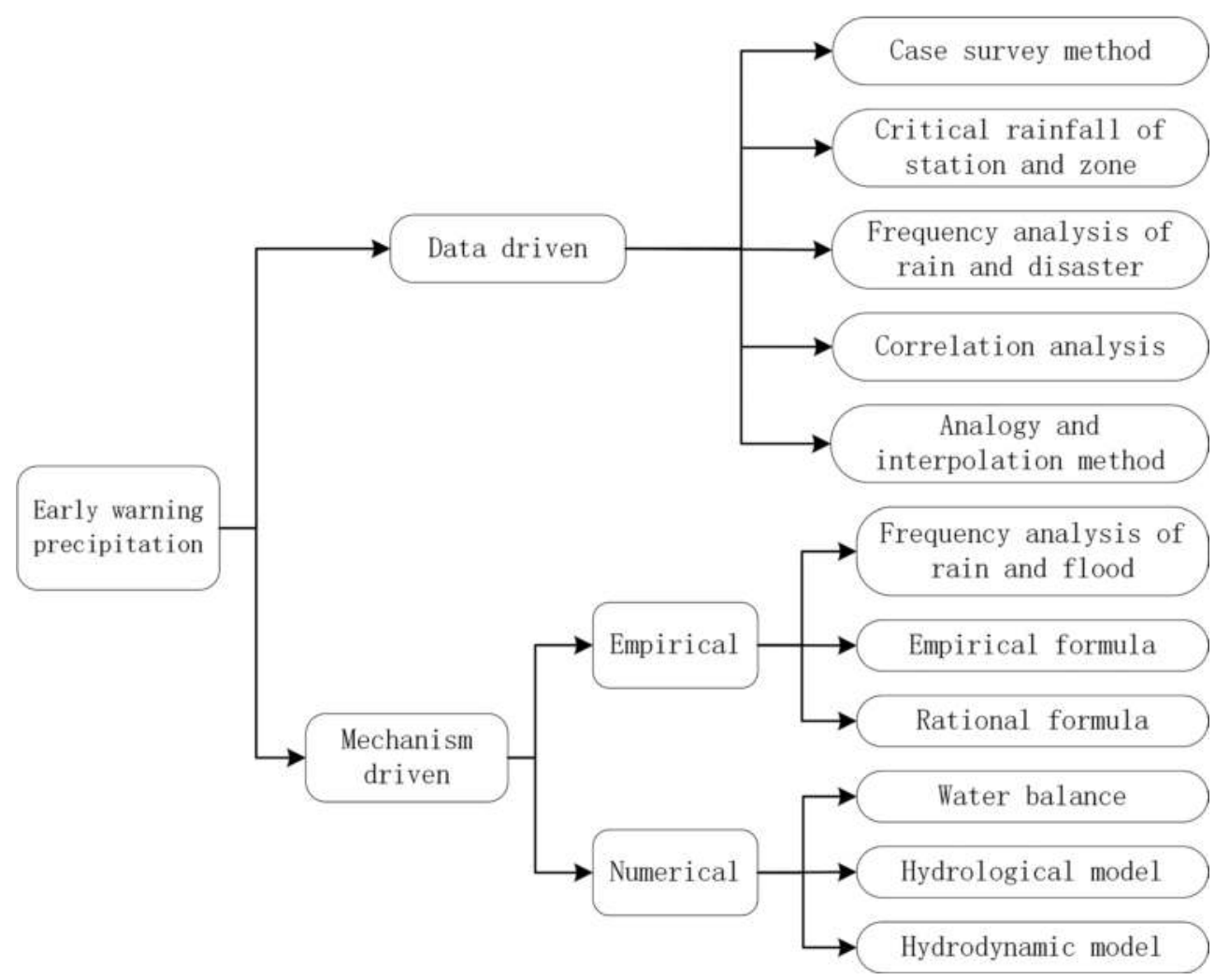

Figure 3. The methods of calculating early warning rainfall. 
critical rainfall, frequency analysis of rain and disaster, correlation analysis, analogy method and interpolation method [27].

The case survey method is to get critical rainfall amounts via statistic of rainfall amounts in the historical disasters. To be specific by taking the minimum rainfall amounts of each time interval as the initial value of early warning rainfall and comparing it with the value of adjacent areas to determine the final rainfall amounts for flash flood early warning. If sufficient historical data are available from existing hydrological observation network or meteorological observation network, then critical rainfall for each station and region would be calculated (Eq. (2)).

$$
R_{t i}=\operatorname{Min} R_{t i j}(j=1, \ldots, N)
$$

In Eq. (2), $t$ is the time period; $i$ is the order number of precipitation station; $j$ is the order number of historical flash flood disaster; $R_{t i}$ refers to the critical rainfall amount and $R_{t i j}$ is the maximal precipitation amount of station ' $i$ ' during time period ' $t$ ' in flash flood disaster ' $j$ '.

If the number of precipitation station in analysis is 1 , the $R_{t i}$ means the single station critical rainfall. When the number of precipitation station increased, the regional critical rainfall can be analysed. With sufficient historical disaster data, Wang et al. calculated the single station critical rainfall and the regional critical rainfall for flash flood early warning in Chengde city [28].

Based on the assumption that rainfall and flash flood disasters have the same frequency, Bin and Dou calculated the frequency of flash flood disasters in Urumqi city and then inferred the early warning rainfall amounts in the same frequency [29].

Duan analysed the flash flood rainfall values of typical small watershed in the Yellow river by multiple methods, such as single station critical rainfall method, regional critical rainfall method, frequency analysis of rain and disaster method, etc., and the difference of computed results is contrasted and analysed [30].

Wang et al. proposed a compositive computational method about mountain mud rock flow critical rainfall, which successively corrects the intermediate result assisted by single station critical rainfall and frequency analysis of rain and disaster and applied this method to make the rainfall zoning of Hubei province [31]. Follow this, Zhao et al. calculated early warning rainfall in Linqu county by the determination method which combines the single station critical rainfall method and P-III frequency analysis method [32]. Yan et al. utilized $24 \mathrm{~h}$ precipitation and former 10 days rainfall as a factor for predicting, and combined differentiating and analytic approach to predict flash flood real-time warning in Jiangxi province [33].

With considerable correlation between precipitation and basin parameters, Fan et al. built a statistical model concerned critical precipitation, basin areas, main river length and main river slope (Eq. (3)) and by using this model, the early warning rainfall amounts for 1045 small basins in Jiangxi province has been calculated [34]. What's more, by analysing 1101 cases of mountain torrent and geological hazard data in Yunnan province, Hu et al. calculated the critical rainfall on which five grades for early warning of mountain torrent and geological hazard are based [35]. 


$$
R=a F+b J+c L+d
$$

In Eq. (3), $a, b, c$ and $d$ are constants calibrated by using pre-existing critical rainfall values; $F$ is the drainage area; $J$ is the gradient of main stream; $L$ is the length of main stream and $R$ is the critical rainfall to be calculated.

Liu et al. and Ye et al. proposed a flash flood early warning method based on dynamic critical precipitation, which closely correlated with soil moisture saturation [36, 37]. This approach was applied in Suichuanjiang river basin and Pihe river basin for flash flood forecasting and early warning.

Besides these methods, there are two special methods, analogy method and interpolation method, which could be used to infer objective critical rainfall from nearby ones calculated by other methods [38]. Based on pre-existing early warning rainfall values of flash flood disasters in Yunnan province, Zhang et al. carried out the research to the variety regulation of the critical rainfall by the application of the Kriging of special gridding method, the inverse distance to a power method, the radial basis function method and then drew up each isoline maps [39].

The kernel of the mechanism-driven methods is searching critical rainfall responding to the water level at which flash flood disasters will be caused. A technical route of these methods is 'based on the correlation between water level and discharge, and the correlation between rainfall and discharge, calculating disaster-causing discharge according to disaster-causing water level, then calculating disaster-causing rainfall according to disaster-causing discharge'. Follow this path, Ye et al. came up with the anti-water method for calculating critical rainfall in Zhejiang province [40].

Furthermore, these mechanism-driven methods can be classified into empirical method and numerical model method. But for the lacking of data, even these methods are driven by the disaster mechanism, the major solution for measuring the correlation between water level and discharge is still rely on experiences in practice.

The empirical method also called the black box method, which could be subdivided into frequency analysis of rain and flood, empirical formula method and rational formula method. Based on the assumption that rainfall and flash flood disasters have the same frequency, Liu et al. and Zhang et al. calculated the critical frequency corresponding to the critical flow rate, analysed the cumulative distribution interval points of probability and determined the method for calculating the critical rainfall in the data-deficient region [41, 42]. Empirical formula and rational formula are similar in calculating design rain and floods with different principle. Based on the correlation analysis, empirical formula is concluded from practical experience and embodies the regional characteristics. This kind of method concludes china institute of water resources and hydropower research (IWHR) hydrology empirical formula, research institute of highway ministry of transport ( $\mathrm{RIOH})$ empirical formula, regional unit hydrographs and empirical unit hydrographs summarized by each hydrographic office of provinces or cities. By simplifying and generalizing the processes of runoff formation, the rational formula is derived for calculating the discharge of specific river cross-section (Eq. (4)). The research of flash flood early warning precipitation in Jiangxi province showed that the 
rational formula method usually has more stable results with smaller error than data-driven methods [43]. In order to raise the accuracy of early warning precipitation, a method for calculating the geographic distribution rules of flow concentration parameters and the spatial distributing rules of rainstorm parameters is put forward [44].

$$
Q=0.278 \times \frac{a S}{t^{n}} \times F
$$

Eq. (4) is the fundamental form of rational formula, $Q$ is the design flood, $a$ is a constant reflecting the losses of flood peak, $S$ is the maximum of hourly rainfall, $t$ is the basin flow concentration time, $n$ is decline exponent of rainstorm and $F$ is the drainage area.

Since the data of flash flood disasters are continuously increasing, more and more scholars start taking part in researching numerical model for calculating flash flood real-time warning indicators. These numerical models are usually built that rely on water balance, principles of hydrology or hydrodynamics. Based on the water balance equation, Jiang and Shao put forward a concept and proposed a calculation method of minimum critical rainfall with awareness that criteria warning standard should take both rainfall amount and intensity into account [45]. For warning in ungauged basins, Ye et al. proposed an approach that using an antecedent precipitation index method and a Nash model for runoff forecasting [46]. Furthermore, considering the soil moisture and observed antecedent rainfall, Chen et al. established the calculation functions for dynamic critical precipitation under different soil moisture content levels by using the fitted function relation between antecedent rainfall and critical rainfall by the least square method [47]. Guo et al. designed a flash flood warning system based on a distributed hydrological model and evaluated its practical application in Henan province [48]. Li et al. introduced the basic concepts and methods of using a distribution hydrological model technique with detailed sub-basin delineation to analyse indicators for flash flood early warning [49]. Based on the full hydrodynamic model, Wang et al. proposed a new approach to calculate the distributed threshold rainfall for flash flooding, which constitutes the basis for effective flash flood warning [50]. Wen and Zhang et al. used a 2-D dynamic flood evolution model 'FloodArea' to simulate flash flood inundation caused by different rainfall amount for refined flash flood early warning in mountain area with small watershed and no hydrological data [51-53].

\subsection{Improving data sources used for warning}

The main restriction to flash flood real-time early warning is the lack of real-time rainfall data, discharge data and water level data. The direct and efficient approach to solve this problem is to increase monitoring network for weather, rainfall and river situation. For guiding hydro-meteorological monitoring network layout in mountain flood prevention areas, Chen et al. and Yuan et al. put forward a technical principle and index for the layout of hydro-meteorological stations according to the needs of mountain flood prevention in China [54,55]. In addition, Shu and Han also analysed the density of rainfall monitoring network in Suichuanjiang river basin by using the method of extracting stations and watershed model method [56].

Along with the construction of traditional hydro-meteorological monitoring network, scholars also explored the application of remote sensing technology in obtaining data and 
tried to extend forecast period via introducing advanced weather forecast technology. According to the needs of flash flood disaster survey and valuation, Liu et al. used the data of laser point cloud to automatically measure the elevation of households along the river and vertical and horizontal sections of river channel and proved that could save time and cost with more abundant data [57]. Liao tried to use the data from radar with high timespace resolution and the data from automatic rainfall station to monitor the real-time strong rainfall, which is significant for the early warning of flash flood disaster [58]. Furthermore, Liu et al. showed that how forecaster use the monitoring data of TWR01A weather radar to warn about flash flood disaster [59]. But it is still difficult to forecast flash flood just rely on real-time monitoring data. Facing this, Li et al. tried to use the ensemble forecast approach, which constructed by various physical processes of a mesoscale model, to extend forecast period for flash flood early warning [60]. Qiu and Zi and Zi et al. also studied the application of quantified precipitation forecast technology in mountain areas and proved its applicability in flash flood early warning $[61,62]$. Furthermore, Chen and Li simulated the historic flash flood occurred in Yangtze river basin on the basis of the weather research and forecasting (WRF) model to explore the optimal combination of physical schemes for the flash flood early warning [63].

\subsection{Information construction of warning systems}

Informatization is quite necessary for shortening the delay time of each step for flash flood real-time warning. Flash flood early warning information construction, covering data acquisition, transmission, early warning analysis, disaster simulation and warning broadcasting could greatly enhance the capability of flash flood real-time warning. Considering particularity of environment in mountain areas, Meng designed a data acquisition unit with low power consumption, stable performance and high precision [64]. Zhong developed a river water level remote monitoring and early warning instruments by using the water level data collection which is based on static pressure sensor of input style and the general packet radio service (GPRS) and short messaging service (SMS) technology [65]. With the aid of code division multiple access (CDMA)/GPRS communication product, Fei and Huang designed an intelligence transmission system, which could provide unimpededly, fast, reliable and stable communication channel for transmission of flash flood real-time warning signals [66]. Zhang et al. and Hao et al. designed a flash flood geological disaster early warning system based on the Internet of Things (ToH) which combine the information sensor subsystem with data acquisition subsystem $[67,68]$. Based on the distributed hydrological model and dynamic critical precipitation method, $\mathrm{Hu}$ and Liu developed a prototype medium and small river flash floods forecasting and warning systems and did a case study in Suichuan river basin [69]. To improve operational capacity of county flood control department in monitoring and early warning of flash floods, Zhang put forward an event-driven county-level flash flood monitoring and early warning system and applied it in Luanchuan country [70]. Moreover, Zhang designed a flash flood early warning information system based on the technology of GIS, spatial database and computer networking [71]. Jin and Wang summarized the implementation methods of the WebGIS and rich Internet application (RIA) technology solutions and developed the country-level flash flood early warning system separately by Silverlight technology or Flex technology [72, 73]. Furthermore, Li, Xiu, Lu and Lin designed their own 
flash flood disaster early warning system separately in Shandong province, Xinjiang province, Dinghu city or Yueyang city [74-77].

\section{Future studies}

Chinese scholars have done a lot of studies about flash flood early warning, containing longterm warning and real-time warning. Overall, the research of flash flood early warning in China is still in a preliminary stage and there are still numerous issues need to be solved:

1. After long time practices, the research about flash flood disaster has been developed from qualitative analysis to quantitative estimation. But the restrictive relation and influence relation between flash flood disasters causing factors, pregnant environments and bearing body are still need to be quantitatively analysed into depth.

2. The flash flood long-term warning and real-time warning are quite separated with each other in the present research. It has practical implication to consider the long-term warning achievement in real-time warning analysis in the future study.

3. The flash flood early warning indicator system need to be completed as soon as possible. And the type and the form of indicators need to be expanded for more comprehensive consideration. For example, trying to take flow change rate, water level change rate, flow velocity, flow velocity change rate, etc. into an early warning indicator system.

4. More types of multi-sources data could be utilized in flash flood early warning and more data usages should be explored. Such as obtaining soil water content via remote sensing retrieval for improving flash flood mechanism-driven model results. Or doing ensemble early warning of flash flood according to the ensemble weather forecast data, etc.

\section{Acknowledgements}

The authors are grateful to the National Key Research and Development Project of China (no. 2016YFC0401903) for financial support for this research.

\section{Author details}

Haichen Li, Tao Qin and Xiaohui Lei*

*Address all correspondence to: 1xh@iwhr.com

State Key Laboratory of Simulation and Regulation of Water Cycle in River Basin, China Institute of Water Resources and Hydropower Research, Beijing, China 


\section{References}

[1] Zuo D, Wang S. An Encyclopedia of Architecture \& Civil Engineering of China. 1st ed. Beijing: China Architecture \& Building Press; 2008

[2] Liu R, Wang F, Shi S. China Agriculture Encyclopedia. 1st ed. Beijing: China Agriculture Press; 1987

[3] Hongxia LI, Qin G, Wang X, Miao R, Liu Y. Advances in study on flash flood forecast and warning. Journal of China Hydrology. 2014;34(05):12-16

[4] Liu Z. Research and application of forecasting technology in flash flood. China Flood \& Drought Management. 2012;22(02):41-45,50

[5] Ren G, Feng G, Yan Z. Progress in observation studies of climate extremes and changes in mainland China. Climatic and Environmental Research. 2010;15(04):337-353

[6] Ministry of Water Resources of the People's Republic of China. Bulletin of Flood and Drought Disasters in China 2014. 1st ed. Beijing: China Water \& Power Press; 2014

[7] Zhang Z. Characters of mountain flood disasters in China and prevention methods. China Water Resources. 2007;(14):14,15

[8] Ma J, Hu W. China's flash flood disaster and its control measures. Yangtze River. 2005; 36(06):3-5

[9] Zhou J, Wang L, Xie B, Rao L. A review on the technique of forecasting and alarming flash flood and debris flow disaster. Journal of Mountain Research. 2001;19(06):527-532

[10] Wei Y, Xie Y. Study on prediction models of precipitation-typed debris flow. Journal of Natural Disasters. 1990;6(02):82-88

[11] Zhong D, Xie H, Wang A. Pre-estimate and forecast parameter of debris flows along Chengdu-Kunming railway in Sichuan province. Journal of Mountain Research. 1990; 8(02):82-88

[12] Xie Y, Cui Z. The prevention and forecast of debris flows in Beijing mountain areas. Guizhou Science. 1992;(03):132

[13] Sun H, Sha Y, Huang Z. Review of present situation in studying mountain torrent disaster. Journal of Yangtze River Scientific Research Institute. 2004;21(06):77-80

[14] Liu H, Tang C. Designing and application of debris flow information system in country grade: A case study in Danba country, Sichuan province. Arid Land Geography. 1997;20(04):61-67

[15] Zhou J. Technique of space prediction on flush flood and debris flows disaster. Journal of Soil Water Conservation. 2001;15(02):112-116

[16] Liu X. Discussion on debris-flow out breakability zoning. Journal of Catastrophology. 1989;4(04):3-9 
[17] Zhong D, Xie H, Wei F. Research on the regionalization of debris flow danger degree in the upper reaches of Changjiang River. Mountain Research. 1994;12(02):65-70

[18] Hou J, Han M, Wan B, Zheng S, Zhang W, Zhong Y. Developmental pattern and risk regions prediction of debris flow in Liaoning province. The Chinese Journal of Geological Hazard and Control. 1990;1(04):46-54

[19] Zhou C, Wan Q, Huang S, Chen D. A GIS-based approach to flood risk zonation. Acta Geographica Sinica. 2000;55(01):15-24

[20] Zhao S. Hazard assessment for mountain torrents on the upper reach area of Minjiang river. Geographical Research. 1997;16(01):98-103

[21] Tang C, Shi Y. Approach to mutil-objectives assessment for urban torrent hazard. Progress in Geography. 2006;25(04):13-21

[22] Guan M, Chen X. Research of regional torrent risk zonation in Jiangxi province. Torrential Rain and Disasters. 2007;26(04):339-343

[23] Zhu J, Tang C. Vulnerability analysis of urban flash floods. Journal of Chengdu University of Technology (Science \& Technology Edition. 2008;35(01):61-67

[24] Zhu J. Urban flash-flood risk assessment: A case study in Wenshan city, Yunnan. Geographical Research. 2010;29(04):655-664

[25] Lin X, Lin Q, Wang M, Zhao Y, Li Y. Hazard zoning of flash flood in mountainous administrative region of town: A case study on Tiaoshi town. Journal of Natural Disasters. 2015,24(3):90-96

[26] Xu X, He W. Study on risk grade partition of mountain torrent disaster based on land utilization analysis. Jiangxi Hydraulic Science \& Technology. 2015;41(04):283-290

[27] Chen G, Yuan Y. Research on critical precipitation amount computation method of mountain torrential flood disaster. Yangtze River. 2005;36(12):40-43

[28] Wang H, Wang Z, Lu Y, Gao Y. Research on hydrological warning and practical of mountain torrents disaster in Chengde city. Water Sciences and Engineering Technology. 2016;(01):10-13

[29] Bin J, Dou X. Study on the critical rainfall distribution and prevention and control regionalization of mountain flood disasters in Urumqi. Research of Soil and Water Conservation. 2005;12(05):256-259

[30] Duan S. Computing methods for rainfall thresholds of flash flood in typical small catchments. Water Resources Planning and Design. 2009;(02):20-21

[31] Wang R, Zhou Y, Wang L, Ke Y. The studies on mountain mud-rock flow critical rainfall and rainfall zoning of Hubei province. Plateau Meteorology. 2006;25(02):330-334

[32] Zhao R, Wang M, Lu X. Research on determination method for rainfall warning indexes of torrential flood disaster. Water Resources and Power. 2011;9(09):49-53 
[33] Yan H, Zhu J, Liao H. The mountain torrents calamity of Jiangxi is distributed the characteristic and forecast preliminary studies. Jiangxi Meteorology Science \& Technology. 2005;28(2):27-30

[34] Fan J, Shan J, Guan M, Xu X. Research on analysis and calculation method of critical precipitation of mountain torrents in Jiangxi province. Meteorological Monthly. 2012;38(09):1110-1114

[35] Hu J, Min Y, Li H, Li X, Li C, Li l. Meteorological early-warning research of mountain torrent and geologic hazard in Yunnan province. Journal of Catastrophology. 2014;29(01):62-66

[36] Liu Z, Yang D, Hu J. Dynamic critical rainfall-based torrential flood early warning for medium-small rivers. Journal of Beijing Normal University (Natural Science). 2010;46(03):317-321

[37] Ye J, Li Z, Chang L. Research and application of flash flood early warning method based on dynamic critical precipitation. Meteorological Monthly. 2014;40(01):101-107

[38] Cheng W. A review of rainfall thresholds for triggering flash flood. Advances in Water Science. 2013;24(06):901-908

[39] Zhang Y, Wang L, Li J, Wang R. Research into spacial gridding analysis methods on critical rainfall of mountain disasters in Yunnan province. Journal of Yunnan Agricultural University. 2007;22(04):570-573

[40] Ye Y, Wang Z, Fan B. An analysis method for ascertain critical rainfall of mountain flood disaster of small watershed in ZheJiang Province. Journal of China Hydrology. 2008;28(01):56-58

[41] Liu Y, Hu C, Zhang H, Liu S. Analysis on method for determination of critical rainfall of mountain torrent disaster in data deficient region. Water Resources and Hydropower Engineering. 2014;45(08):15-17

[42] Zhang H, Liu S, Liu Y, Hu C. Research on the critical rainfall of flash flood in mountainous areas. Journal of China Institute of Water Resources and Hydropower Research. 2014;12(02):185-189

[43] Guan M, Shen S, Shan J. Research on Jiangxi torrential rain and flash flood model. Meteorology and Disaster Reduction Research. 2008;31(02):53-57

[44] Xie P, Chen G, Li D, Xiong L. Study on the parameter laws of rational formula for design flash flood calculation of small basins in Urumchi region. Journal of Mountain Science. 2006;24(04):410-415

[45] Jiang J, Shao L. Standard of mountain flood warning based on the precipitation observation data. Journal of Hydraulic Engineering. 2010;41(04):458-463

[46] Ye J, Li Z, Wu Y. Study and application of flash flood warning method for ungauged basins. Journal of Hydroelectric Engineering. 2013;32(03):15-19 
[47] Chen Y, Yang W, Xu Y. Study of dynamic critical precipitation drafted method under different soil moisture content level. Yangtze River. 2015;46(12):21-26

[48] Guo L, Tang X, Kong F. Studies on mountain flood warning system based on distributed hydrological model and its application. China Water Resources. 2007;(14):38-41

[49] Li C, Guo L, Liu C, Sun D. Flash flood early-warning indicators based on distributed hydrological model-A case study in south branch of Censhui watershed. China Flood \& Drought Management. 2015;25(01):70-76

[50] Wang X, Cao Z, Tan G. Shallow water hydrodynamic modelling of rainfall-induced flash flooding. Engineering Journal of Wuhan University. 2009;42(04):413-416

[51] Wen M, Lin X, You L, Tang Z, Gao J, Zhang R. Risk rainfall assessment methods of flash flood disaster. Meteorological Monthly. 2013;39(10):1325-1330

[52] Zhang L, Wang W, Wen M, Shi Z. Research on refined early-warning method of mountain flood disaster based on flood area. Journal of Fudan University (Natural Science). 2015;54(03):282-287

[53] Zhang M, Li M, Dai C, Huang W. Simulation study of flood in Yunnan based on the flood area model. Journal of Catastrophology. 2016;31(01):78-82

[54] Chen G, Yuan Y, Guo J, Shen H. Layout of hydro-meteorological station network for mountain flood prevention. China Water Resources. 2007;(14):42,43,52

[55] Chen J, Lin C, Chen W. Layout of precipitation station network for mountain flood prevention. Agriculture and Technology. 2015;35(02):201

[56] Shu D, Han J. Discussion on rainfall station network density for torrential disaster monitoring. Journal of China Hydrology. 2015;31(21):49-51

[57] Liu C, Sun T, Zhang Q, Tang X, Guo L. Application of unmanned aerial vehicle laser radar technology in mountain flood survey and evaluation. China Water Resources. 2015;(21):49-51

[58] Liao M. Application of Doppler radar in early warning of mountain flood disasters. Journal of Agricultural Catastrophology. 2012;2(04):84-88

[59] Liu F, Fan J, Zheng Y, Zhang Q. Application of TWR-01A weather radar in flash flood warning in Xi country, Shanxi province. China Flood \& Drought Management. 2013;23(03):31-33

[60] Li J, Liao Y, Zhang B, Shen T. The preliminary application of ensemble prediction in flash flood forecasting. Plateau Meteorology. 2007;26(04):854-861

[61] Qiu H, Zi L. Trial application of WRF model in early warning and forecast of mountain torrent disaster. Yangtze River. 2013;44(13):5-9

[62] Zi L, Yang W, Yuan Y, Qiu H. Experimental study of forecasting and early-warning technology for mountain torrent disasters based on rainfall threshold. Yangtze River. 2015;46(11):10-14 
[63] Chen C, Li J. Yangtze River. Comparative experiment on different combination of physics schemes of WRF model in mountain torrent early-warning. 2015;46(07):60-63

[64] Meng H. Study on mountain flood warning system based on growing-pruning neural network [thesis]. Wuhan: Wuhan University of Science and Technology; 2014

[65] Zhong J. Development of remote monitoring and early warning system for floods in mountainous areas [thesis]. Chengdu: Chengdu University of Technology; 2013

[66] Fei J, Huang L. The design of early warning system about mountain torrents disaster based on GPRS/CDMA correspondence. Technological Development of Enterprise. 2015;28(05):47-49

[67] Zhang C, Gong M. Mountain torrent disaster prediction and alarming system based on the IoT. Communications Technology. 2013;46(02):62-63

[68] Hao M, Zhang J, Zhang Q, Liang H, Li J. Research on the mountain torrent geological disaster defense system based on the Internet of Things. Geospatial Information. 2015;13(05):47-49

[69] $\mathrm{Hu}$ J, Liu Z. Development and application of flash forecasting and warning system for medium-and small-size river basins. Journal of China Hydrology. 2011;31(03):18-21

[70] Zhang H. Study on the flood risk management and technology of the small mountain watershed [thesis]. Beijing: China Institute of Water Resources \& Hydropower Research; 2013

[71] Zhang L. The design of flash flood early warning information system based on WebGIS. Yangtze River. 2009;40(17):84,85,93

[72] Jin X. The design and achievement of prefectural mountain flood disaster warning system which is based on WebGIS [thesis]. Shanghai: East China Institute of Technology; 2012

[73] Wang L. Country-level flash flood warning WebGIS dissemination system based on RIA [thesis]. Jilin: Jilin University; 2014

[74] Li X. Design and implementation on the pre-alarming and supervising system of mountain torrents disaster in Shandong province [thesis]. Dalian: Dalian University of Technology; 2015

[75] Xiu F. Analysis and design of Xinjiang mountain flood disaster monitoring and early warning information sharing management system [thesis]. Xiamen: Xiamen University; 2014

[76] Lu X. Research on the application of monitoring and warning system in the prevention and control of the mountain torrent disaster in Dinghu district of Zhaoqing city [thesis]. Tianjin: Tianjin University; 2014

[77] Lin D. Design and implementation of prewarning information system for Yueyang municipal mountain flood disaster [thesis]. Hunan: Hunan University; 2014 
